\title{
Mechanism Underlying Increase of the Serum Magnesium Concentration Observed Following Treatment with Sodium-Glucose Cotransporter 2 Inhibitors
}

\author{
Yasuhiro Sasaki¹, Keiko Koyano², Shuhei Iida ${ }^{2}$, Tatsuo Yanagawa ${ }^{1,2 *}$ \\ ${ }^{1}$ Department of Medicine, Nerima General Hospital, Tokyo, Japan \\ ${ }^{2}$ Public Interest Incorporated Foundation, Tokyo Healthcare Foundation, Institute for Healthcare Quality Improvement, Tokyo, \\ Japan \\ Email: *tyana-mj@xj9.so-net.ne.jp
}

How to cite this paper: Sasaki, Y., Koyano, K., Iida, S. and Yanagawa, T. (2017) Mechanism Underlying Increase of the Serum Magnesium Concentration Observed Following Treatment with Sodium-Glucose Cotransporter 2 Inhibitors. Journal of Diabetes Mellitus, 7, 241-248.

https://doi.org/10.4236/jdm.2017.74019

Received: August 27, 2017

Accepted: September 19, 2017

Published: September 22, 2017

Copyright $(9) 2017$ by authors and Scientific Research Publishing Inc. This work is licensed under the Creative Commons Attribution International License (CC BY 4.0).

http://creativecommons.org/licenses/by/4.0/

cC) (i) Open Access

\begin{abstract}
Aim: The EMPA-REG OUTCOME study reported that the sodium-glucose cotransporter 2 inhibitor (SGLT2-i) suppressed cardiovascular (CV) events in patients with type 2 diabetes; we recently suggested that increase of the serum magnesium $(\mathrm{Mg})$ by SGLT2-i's can, in part, explain this reduction. The objective of this study was to elucidate the mechanism underlying the elevation of the serum Mg level induced by treatment with SGLT2-i's. Methods: We analyzed the data of 37 patients with type 2 diabetes who underwent clinical evaluation and laboratory assessment at baseline and the end of 3 months. To investigate the relationship between the changes in the serum $\mathrm{Mg}$ concentrations during 3 months' treatment $(\Delta \mathrm{Mg})$ and other variables, we carried out simple linear regression analysis and multiple linear regression analysis. Results: Three months' treatment with the SGLT2-i resulted in a significant improvement of the body weight (BW), BMI, hemoglobin Alc (HbAlc), and fasting plasma glucose levels. The serum $\mathrm{Mg}$ increased significantly. Simple linear regression analysis revealed an association between the $\Delta \mathrm{Mg}$ and the serum triglyceride, serum $\mathrm{Mg}$ at baseline, change of the $\mathrm{BW}(\Delta \mathrm{BW})$, and change of the HbAlc. Multiple linear regression analysis revealed a significant association between the $\Delta \mathrm{Mg}$ and the serum $\mathrm{Mg}$ level at the baseline $(\mathrm{r}=$ $-0.55, \mathrm{P}<0.001)$ and the $\Delta \mathrm{BW}(\mathrm{r}=-0.34, \mathrm{P}<0.05)$. Conclusion: Our study revealed that a lower serum $\mathrm{Mg}$ level at the baseline and $\mathrm{BW}$ reduction were significantly associated with an increase in the serum $\mathrm{Mg}$ following 3 months' treatment with SGLT2-i's.
\end{abstract}




\section{Keywords}

Diabetes, Magnesium, Cardiovascular Events, Sodium-Glucose Cotransporter 2 Inhibitors, The EMPA-REG OUTCOME Study

\section{Introduction}

The EMPA-REG OUTCOME study revealed that the sodium-glucose cotransporter 2 inhibitor (SGLT2-i) empagliflozin suppressed the occurrence of cardiovascular events (CV) in patients with type 2 diabetes within a short period after the start of treatment [1]. This rapid effect of the drug is difficult to explain based on the beneficial effect of empagliflozin on the glucose and lipid metabolism, which is of much slower onset. Various hypotheses have been proposed, and the ketone body hypothesis and hematocrit hypothesis have attracted the most attention [2]; however, the precise mechanism(s) remain unknown.

It has been reported that treatment with SGLT2-i's induces an increase of the serum magnesium $(\mathrm{Mg})$ levels [3] [4]. We recently suggested that the increase of the serum Mg level associated with SGLT2-i treatment could explain, at least in part, the reduction of the CV risk observed in the EMPA-REG OUTCOME study [5], because hypomagnesemia is known to be associated with an elevated risk of $\mathrm{CV}$ events and several studies have shown a reduction in the risk of $\mathrm{CV}$ events associated with improvement of hypomagnesemia [6] [7]. However, the mechanism of increase in the serum Mg induced by SGLT2-i treatment remains unknown [3]. Hypomagnesemia has been reported to be associated with various factors, including obesity, metabolic syndrome, elevated blood glucose, diuretic use, alcohol dependence, diarrhea, etc. [8]; therefore, we considered these factors as candidates associated with an increase in the serum Mg levels after SGLT2-i treatment. The objective of this study was to elucidate the mechanism underlying the elevation of the serum Mg level induced by treatment with SGLT2-i's.

\section{Methods}

\subsection{Subjects, and Physical and Laboratory Examination Findings}

This is a prospective cohort study, and patients recruited for this study were between 40 and 80 years of age, with type 2 diabetes who had been started on treatment with SGLT2-i's in the period between June 2014 and April 2016 at the Nerima General Hospital. We excluded patients who were treated with insulin, GLP-1 analogues or Mg preparation. After obtaining informed consent, 37 outpatients were enrolled in the study.

Type 2 diabetes mellitus was diagnosed according to the Japan Diabetes Association criteria [9]; Confirmation of chronic hyperglycemia is essential for the diagnosis of diabetes mellitus. When plasma glucose levels are used to determine the categories of glycemia, patients are classified as having a diabetic type if they meet one of the following criteria: (i) fasting plasma glucose level of $\geq 126 \mathrm{mg} / \mathrm{dL}$ 
( $\geq 7.0 \mathrm{mmol} / \mathrm{L})$; (ii) 2 -h value of $\geq 200 \mathrm{mg} / \mathrm{dL}(\geq 11.1 \mathrm{mmol} / \mathrm{L})$ in $75 \mathrm{~g}$ oral glucose tolerance test (OGTT); or (iii) casual plasma glucose level of $\geq 200 \mathrm{mg} / \mathrm{dL}(\geq 11.1$ $\mathrm{mmol} / \mathrm{L})$. Re-examination is conducted on another day, and if "diabetic type" is reconfirmed, diabetes mellitus is diagnosed. HbA1c $\geq 6.5 \%$ is now also considered to indicate diabetic type. if the plasma glucose values (any of criteria) and the $\mathrm{HbA} 1 \mathrm{c} \geq 6.5 \%$ in the same blood sample both indicate diabetic type, diabetes mellitus is diagnosed based on the initial examination alone.

All the patients underwent a clinical evaluation and laboratory assessment. The body mass index (BMI) was calculated using the following equation: weight (in kilograms) divided by height (in meters) squared. The fasting plasma glucose (FPG), hemoglobin A1c (HbA1c) (NGSP), serum levels of triglyceride (TG), high-density lipoprotein cholesterol (HDL-C), aspartate aminotransferase (AST), alanine aminotransferase (ALT), creatinine $(\mathrm{Cr})$, magnesium $(\mathrm{Mg})$, and the urine magnesium-to-creatinine ratio $(\mathrm{u}-\mathrm{Mg} / \mathrm{cr}$ ) were measured at the start of treatment and at the end of 3 months' treatment. The data at 3 months minus the data at the baseline are expressed as $\Delta$. (e.g., $\Delta \mathrm{Mg}$ ( $\mathrm{Mg}$ concentration at 3 months) - (Mg concentration at the baseline))

\subsection{Laboratory Methods}

HBA1c was estimated using enzyme immunoassay kits (Abbott Diagnostics, Illinois). A glucose analyzer (glucose oxidase method) was used for the blood glucose estimation. The biochemical analyzer TBA-80FR (Toshiba, Tokyo, Japan) was used for determination of the serum TG, HDL-C, TC, AST, ALT, Mg and $\mathrm{Cr}$ by enzymatic methods.

\subsection{Statistical Analysis}

Data are presented as the means \pm SD. Differences in the parameters between the groups were compared using the Student t-test for paired data.

To investigate the relationships between the $\Delta \mathrm{Mg}$ and other variables, a simple linear regression analysis was performed. A multiple linear regression analysis was used to identify predictors of the $\Delta \mathrm{Mg}$. The main objective is to examine the correlation between $\Delta \mathrm{Mg}$ and various parameters. When assuming that the correlation coefficient is 0.4 or more, calculating necessary samples will be 24 and sample size 37 is enough.

The statistical analyses were performed using the Systat J11 software (Hyulinks, Chicago, IL, USA). P values of $<0.05$ were considered as indicating significance.

\subsection{Ethical Approval}

The present study was conducted in full accordance with the World Medical Association Declaration of Helsinki. The study protocol was reviewed and approved by the Ethics Committee at the Public Interest Incorporated Foundation, Tokyo Healthcare Foundation. Informed consent was obtained from patients. 
All patient data were anonymized prior to the analysis.

\section{Results}

\subsection{Patient Characteristics at the Baseline and after 3 Months of Treatment with a SGTL2-I (Table 1)}

The study cohort consisted of 25 men and 12 women, with a mean age of $55.4 \pm$ 9.3 years and a mean duration of disease of $8.4 \pm 5.6$ years. One patient was drug-naive, 33 patients were receiving metformin, 29 patients had received dipeptidyl-peptidase 4 inhibitors (DPP4-i), 28 patients had received both metformin and DPP4-i, 8 patients had received sulfonylureas, 6 patients had received glinides, 6 patients had received alpha-glucosidase inhibitors, and 4 patients had received pioglitazone. Twenty-four patients were receiving antihypertensive medications and 15 patients were receiving statins.

Treatment with SGLT2-i induced a significant improvement of the body weight (BW), BMI, HbA1c, and FPG level after 3 months of treatment. Serum $\mathrm{Mg}$ increased from $1.9 \pm 0.2$ to $2.0 \pm 0.2 \mathrm{mg} / \mathrm{dL}$ after the start of treatment with an SGLT2-i. No change was observed in the urinary magnesium-to-creatinine ratio. The other parameters are summarized in Table 1.

\subsection{Simple Linear Regression Analysis to Identify Factors Associated with the $\Delta \mathrm{Mg}$ (Table 2)}

The parameters entered into the simple regression analysis are shown in Table 2. The results revealed an association of the $\Delta \mathrm{Mg}$ with the baseline serum $\mathrm{TG}(\mathrm{R}$

Table 1. Characteristics at the baseline and after 3 months of treatment.

\begin{tabular}{|c|c|c|c|c|c|c|c|}
\hline & & \multirow{2}{*}{$\mathrm{n}$} & \multicolumn{2}{|c|}{ Base line } & \multicolumn{2}{|c|}{ After treatment } & \multirow{2}{*}{$\mathrm{P}$} \\
\hline & & & mean & $\mathrm{SD}$ & mean & $\mathrm{SD}$ & \\
\hline BW & $\mathrm{Kg}$ & 37 & 82.5 & 12.2 & 80.4 & 12.1 & $<0.01$ \\
\hline BMI & $\mathrm{Kg} / \mathrm{m}^{2}$ & 37 & 30.5 & 4.61 & 29.7 & 4.54 & $<0.01$ \\
\hline HbAlc & $\%$ & 37 & 9.1 & 1.7 & 8.0 & 1.1 & $<0.01$ \\
\hline AST & $\mathrm{U} / \mathrm{L}$ & 37 & 29.1 & 19.6 & 25.9 & 12.7 & 0.26 \\
\hline $\mathrm{ALT}$ & $\mathrm{U} / \mathrm{L}$ & 37 & 32.9 & 18.9 & 28.3 & 15.6 & $<0.03$ \\
\hline HDL & $\mathrm{mg} / \mathrm{dl}$ & 37 & 48.1 & 8.6 & 49.6 & 10.7 & 0.17 \\
\hline $\mathrm{TC}$ & $\mathrm{mg} / \mathrm{dl}$ & 37 & 190 & 46 & 186 & 39 & 0.54 \\
\hline $\mathrm{TG}$ & $\mathrm{mg} / \mathrm{dl}$ & 37 & 228 & 161 & 197 & 94 & 0.19 \\
\hline FPG & $\mathrm{mg} / \mathrm{dl}$ & 37 & 206 & 69 & 166 & 55 & $<0.01$ \\
\hline Cre & $\mathrm{mg} / \mathrm{dl}$ & 37 & 0.75 & 0.18 & 0.79 & 0.18 & $<0.01$ \\
\hline sMg & $\mathrm{mg} / \mathrm{dl}$ & 37 & 1.9 & 0.2 & 2.0 & 0.2 & $<0.02$ \\
\hline $\mathrm{uMg} / \mathrm{Cr}$ & $\mathrm{mg} / \mathrm{gCr}$ & 34 & 58 & 58 & 66 & 49 & 0.051 \\
\hline
\end{tabular}

The data are presented as means $\pm \mathrm{SD}$. Three data of $\mathrm{uMg} / \mathrm{Cr}$ can not be obtained and the number is 34 . Abbreviations: $\mathrm{BW}=$ body weight; HbAlc = hemoglobin Alc (NGSP); Cre = serum creatinine; $\mathrm{TC}=$ serum total cholesterol; TG = serum triglyceride; $\mathrm{HDL}=$ serum high density lipoprotein cholesterol; $\mathrm{AST}=$ serum aspartate aminotransferase; $\mathrm{ALT}=$ serum alanine aminotransferase; $\mathrm{s}-\mathrm{Mg}=$ serum magnesium. $\mathrm{uMg} / \mathrm{cr}=$ urinary magnesium-to-creatinine ratio. 
Table 2. Simple linear regression analysis to determine the relationship of the $\Delta \mathrm{Mg}$ with various parameters.

\begin{tabular}{cccccc}
\hline & $\mathrm{R}$ & P value & & $\mathrm{R}$ & P value \\
\hline Age & 0.29 & 0.08 & & & \\
BW & 0.03 & 0.88 & $\Delta \mathrm{BW}$ & -0.36 & $<0.05$ \\
HbAlc & -0.16 & 0.34 & $\Delta$ HbAlc & 0.54 & $<0.01$ \\
s-Cr & -0.02 & 0.9 & $\Delta \mathrm{s}-\mathrm{Cr}$ & 0.27 & 0.11 \\
TC & $<0.01$ & 1 & $\Delta \mathrm{TC}$ & $<0.01$ & 1 \\
TG & -0.45 & $<0.01$ & $\Delta \mathrm{TG}$ & $<0.01$ & 1 \\
HDL & $<0.01$ & 1 & $\Delta \mathrm{HDL}$ & 0.25 & 0.14 \\
$\mathrm{AST}$ & -0.07 & 0.69 & $\Delta \mathrm{AST}$ & 0.21 & 0.12 \\
ALT & -0.14 & 0.42 & $\Delta \mathrm{ALT}$ & 0.24 & 0.15 \\
$\mathrm{~s}-\mathrm{Mg}$ & -0.69 & $<0.01$ & & & \\
\hline
\end{tabular}

$\mathrm{R}$, correlation coefficient. $\Delta$ : The data at 3 months minus those at the baseline (ex. $\Delta \mathrm{Mg}=(\mathrm{Mg}$ concentration at 3 months) - (Mg concentration at the baseline)). Abbreviations: $\mathrm{BW}=$ body weight; $\mathrm{HbAlc}=$ hemoglobin Alc (NGSP); Cre = serum creatinine; TC = serum total cholesterol; TG = serum triglyceride; $\mathrm{HDL}$ = serum high density lipoprotein cholesterol; AST = serum aspartate aminotransferase; ALT = serum alanine aminotransferase; $\mathrm{s}-\mathrm{Mg}=$ serum magnesium.

$=-0.45, \mathrm{P}<0.001)$ and serum $\mathrm{Mg}(\mathrm{R}=-0.69, \mathrm{P}<0.01)$ and with changes of the BW $(\triangle \mathrm{BW})(\mathrm{R}=-0.36, \mathrm{P}<0.05)$ and HbAlc $(\Delta$ HbAlc $)(\mathrm{R}=0.54, \mathrm{P}<0.01)$ during the treatment.

\subsection{Multivariate Linear Regression Analysis}

To identify the determinants of the $\Delta \mathrm{Mg}$ after 3 months of SGLT2-i treatment, a multiple linear regression analysis was performed. Serum TG, serum $\mathrm{Mg}, \Delta \mathrm{BW}$ and $\triangle \mathrm{HbA} 1 \mathrm{c}$ were regarded as dependent variables, as they were identified by simple linear regression analysis to be significantly associated with the $\Delta \mathrm{Mg}$. The results identified the baseline serum $\mathrm{Mg}$ level $(\mathrm{r}=-0.55, \mathrm{P}<0.001)$ and $\Delta \mathrm{BW}(\mathrm{r}$ $=-0.34, \mathrm{P}<0.05)$ as being significantly associated with the $\Delta \mathrm{Mg}$. The regression equation was as follows:

$\Delta \mathrm{Mg}=1.25-0.64 \mathrm{X}($ initial s $-\mathrm{Mg})-0.02 \Delta \mathrm{BW}\left(\mathrm{R}^{2}=0.54, \mathrm{~F}=20.1, \mathrm{P}<0.01\right)$.

\section{Discussion}

It has been reported that atrial fibrillation develops more frequently in the presence of hypomagnesemia [10] and that type 2 diabetic patients with hypomagnesemia are at a higher risk of developing ventricular extrasystoles [11]. A high incidence of $\mathrm{CV}$ events and sudden death has also been reported in patients with hypomagnesemia [12]. A meta-analysis of relevant studies, including those without diabetes, revealed that elevation of the serum $\mathrm{Mg}$ level by $0.2 \mathrm{mmol} / \mathrm{L}$ was associated with a $30 \%$ decrease in the risk of onset of cardiovascular disease and $40 \%$ decrease in the risk of death from CV events [6]. These favorable effects of $\mathrm{Mg}$ on the cardiovascular system are considered to be attributable to the an- 
ti-inflammatory activity on the vascular endothelium and smooth muscle, vascular relaxant activity and sympatholytic activity of magnesium [8], as well as its hypotensive activity [7]. In the EMPA-REG outcome study, treatment with SGLT2-i's resulted in a remarkable suppression (38\% decrease) of the risk of death from CV events [1], but no conclusion has yet been reached about the mechanism(s) underlying this beneficial effect of this class of drugs. We previously proposed the view that elevation of the serum $\mathrm{Mg}$ level induced by SGLT2-i treatment is probably one of the factors involved in the suppression of the risk of CV events observed in patients treated with this class of drugs [5]. We believe that elucidation of the mechanism underlying the elevation of the serum Mg level induced by treatment with SGLT2-i's is important.

The present study revealed that low serum Mg levels at the baseline (at the start of treatment) and weight loss during the treatment were associated with elevation of the serum Mg level following treatment with a SGLT2-i. The previous finding from the present study is consistent with the report by Gilbert et al. of a greater degree of increase of the serum Mg level induced by SGLT2-i treatment in the group with low baseline serum $\mathrm{Mg}$ levels than in the group with high baseline serum Mg levels [13]. Concerning the association between serum $\mathrm{Mg}$ elevation and weight loss seems to be explained as follows; it is known that serum $\mathrm{Mg}$ levels tend to be low in obese individuals and patients with metabolic syndrome [14]. If weight loss alleviates obesity and metabolic syndrome, the serum $\mathrm{Mg}$ level may be expected to rise.

\section{Limitations}

The present study failed to resolve the following two questions.First, it is known that in the presence of hyperglycemia, excessive glomerular filtration can reduce $\mathrm{Mg}$ reabsorption, leading to hypomagnesemia [15]. If hyperglycemia is corrected, $\mathrm{Mg}$ reabsorption may improve, leading to elevation of the serum $\mathrm{Mg}$ level [16]. In the present study, the urinary $\mathrm{Mg}$ level was analyzed in randomly collected urine samples, and this analysis revealed no change after treatment as compared to the pre-treatment level. Because this analysis did not use the 24-hour urinary output data, it is difficult to arrive at any definitive conclusions. Second, the present study did not incorporate analysis of the possibility of $\mathrm{Mg}$ release from the bones. In a previous study of the markers of ossification and bone destruction, no significant difference was noted between a SGLT2-i treatment group and the control group [17]. It is therefore difficult to comment on $\mathrm{Mg}$ release from the bones into the blood associated with SGLT2-i treatment.

\section{Conclusions}

We previously reported that elevation of the serum Mg level was probably involved in suppression of the onset of CV events in the EMPA-REG outcome study [5]. In the present study, elevation of the serum Mg was found to be associated with weight loss after the start of SGLT2-i treatment and to be more likely 
to occur in patients with low serum Mg levels at the baseline. These findings suggest that patients with hypomagnesemia are more likely to enjoy the beneficial effect of SGLT2-i treatment on the risk of CV events.

\section{COI Statement}

The authors received no financial support for this study. The authors report no conflicts of interest related to this work.

\section{References}

[1] Zinman, B., Wanner, C., Lachin, J.M., Fitchett, D., Bluhmki, E., Hantel, S., Mattheus, M., Devins, T., Johansen, O.E., Woerle, H.J., Broedl, U.C. and Inzucchi, S.E., EMPA-REG OUTCOME Investigators (2015) Empagliflozin, Cardiovascular Outcomes, and Mortality in Type 2 Diabetes. The New England Journal of Medicine, 373, 2117-2128. https://doi.org/10.1056/NEJMoa1504720

[2] Ferrannini, E., Mark, M. and Mayoux, E. (2016) CV Protection in the EMPA-REG OUTCOME Trial: A “Thrifty Substrate” Hypothesis. Diabetes Care, 39, 1108-1114, https://doi.org/10.2337/dc16-0330

[3] List, J.F., Woo, V., Morales, E., Tang, W. and Fiedorek, F.T. (2009) Sodium-Glucose Cotransport Inhibition with Dapagliflozin in Type 2 Diabetes. Diabetes Care, 32, 650-657. https://doi.org/10.2337/dc08-1863

[4] Tang, H., Zhang, X., Zhang, J., Li, Y., Del Gobbo, L.C., Zhai, S. and Song, Y. (2016) Elevated Serum Magnesium Associated with SGLT2 Inhibitor Use in Type 2 Diabetes Patients: Ametaanalysis of Randomised Controlled Trials. Diabetologia, 59, 2546-2551. https://doi.org/10.1007/s00125-016-4101-6

[5] Yanagawa, T. (2017) Is an Increase in Serum Magnesium One of the Causes of Cardiovascular Events Reduction in the EMPA-REG OUTCOME Study? Journal of Clinical Medicine Research, 9, 449-450. https://doi.org/10.14740/jocmr3014w

[6] Del Gobbo, L.C., Imamura, F., Wu, J.H., de Oliveira Otto, M.C., Chiuve, S.E. and Mozaffarian, D. (2013) Circulating and Dietary Magnesium and Risk of Cardiovascular Disease: A Systematic Review and Meta-Analysis of Prospective Studies. The American Journal of Clinical Nutrition, 98, 160-173. https://doi.org/10.3945/ajcn.112.053132

[7] Zhang, X., Li, Y., Del Gobbo, L.C., Rosanoff, A., Wang, J., Zhang, W. and Song, Y. (2016) Effects of Magnesium Supplementation on Blood Pressure: A Meta-Analysis of Randomized Double-Blind Placebo-Controlled Trials. Hypertension, 68, 324-333. https://doi.org/10.1161/HYPERTENSIONAHA.116.07664

[8] Grober, U., Schmidt, J. and Kisters, K. (2015) Magnesium in Prevention and Therapy. Nutrients, 7, 8199-8226. https://doi.org/10.3390/nu7095388

[9] Seino, Y., Nanjo, K., Tajima, N., Kadowaki, T., Kashiwagi, A., Araki, E., Ito, C., Inagaki, N., Iwamoto, Y., Kasuga, M., Hanafusa, T., Haneda, M. and Ueki, K. (2010) Report of the Committee on the Classification and Diagnostic Criteria of Diabetes Mellitus. Journal of Diabetes Investigation, 19, 212-228.

[10] Khan, A.M., Lubitz, S.A., Sullivan, L.M., Sun, J.X., Levy, D. and Vasan, R.S. (2013) Low Serum Magnesium and the Development of Atrial Fibrillation in the Community: The Framingham Heart Study. Circulation, 127, 33-38. https://doi.org/10.1161/CIRCULATIONAHA.111.082511

[11] Del Gobbo, L.C., Song, Y., Poirier, P., Dewailly, E., Elin, R.J. and Egeland, G.M. 
(2012) Low Serum Magnesium Concentrations Are Associated with a High Prevalence of Premature Ventricular Complexes in Obese Adults with Type 2 Diabetes. Cardiovascular Diabetology, 11, 23. https://doi.org/10.1186/1475-2840-11-23

[12] Kieboom, B.C., Niemeijer, M.N., Leening, M.J., van den Berg, M.E., Franco, O.H., Deckers, J.W., Hofman, A., Zietse, R., Stricker, B.H. and Hoorn, E.J. (2016) Serum Magnesium and the Risk of Death from Coronary Heart Disease and Sudden Cardiac Death. Journal of the American Heart Association, 5, e002707. https://doi.org/10.1161/JAHA.115.002707

[13] Gilbert, R.E., Mende, C., Vijapurkar, U., Sha, S., Davies, M.J. and Desai, M. (2017) Effects of Canagliflozin on Serum Magnesium in Patients with Type 2 Diabetes Mellitus: A Post Hoc Analysis of Randomized Controlled Trials. Diabetes Therapy, 8, 451-458.

[14] Weglicki, W.B. (2012) Hypomagnesemia and Inflammation: Clinical and Basic Aspects. Annual Review of Nutrition, 32, 55-71.

https://doi.org/10.1146/annurev-nutr-071811-150656

[15] Gommers, L.M., Hoenderop, J.G., Bindels, R.J. and de Baaij, J.H. (2016) Hypomagnesemia in Type 2 Diabetes: A Vicious Circle? Diabetes, 65, 3-13.

https://doi.org/10.2337/db15-1028

[16] Budoff, M.J. and Wilding, J.P.H. (2017) Effects of Canagliflozin on Cardiovascular Risk Factors in Patients with Type 2 Diabetes Mellitus. International Journal of Clinical Practice, 71, e12948.

http://onlinelibrary.wiley.com/doi/10.1111/ijcp.12948/full https://doi.org/10.1111/ijcp.12948

[17] Bolinder, J., Ljunggren, Ö., Johansson, L., Wilding, J., Langkilde, A.M. and Sjöström, C.D. (2014) Dapagliflozin Maintains Glycaemic Control While Reducing Weight and Body Fat Mass over 2 Years in Patients with Type 2 Diabetes Mellitus Inadequately Controlled on Metformin. Diabetes, Obesity and Metabolism, 16, 159-169. https://doi.org/10.1111/dom.12189 